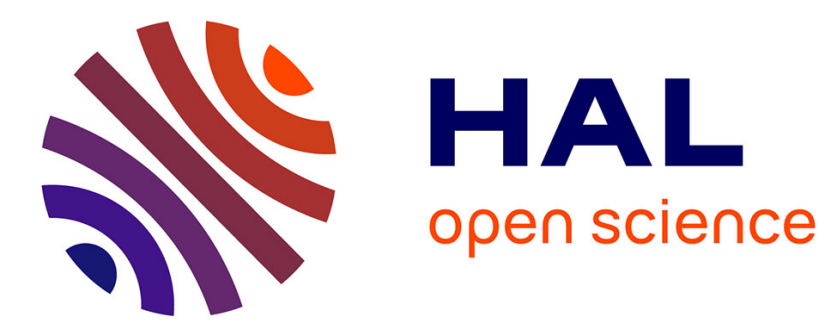

\title{
Mechanics and materials in fretting
}

Léo Vincent, Yves Berthier, Marie-Christine Baietto, Murielle Godet

\section{To cite this version:}

Léo Vincent, Yves Berthier, Marie-Christine Baietto, Murielle Godet. Mechanics and materials in fretting. Wear, 1992, 153 (1), pp.135-148. 10.1016/0043-1648(92)90266-B . hal-01951920

\section{HAL Id: hal-01951920 \\ https://hal.science/hal-01951920}

Submitted on 7 Jul 2021

HAL is a multi-disciplinary open access archive for the deposit and dissemination of scientific research documents, whether they are published or not. The documents may come from teaching and research institutions in France or abroad, or from public or private research centers
L'archive ouverte pluridisciplinaire HAL, est destinée au dépôt et à la diffusion de documents scientifiques de niveau recherche, publiés ou non, émanant des établissements d'enseignement et de recherche français ou étrangers, des laboratoires publics ou privés.

\section{(c)(1)}

Distributed under a Creative Commons Attribution| 4.0 International License 


\title{
Mechanics and materials in fretting
}

\author{
L. Vincent \\ Département Matériaux-Mécanique Physique (CNRS URA 447), Ecole Centrale de Lyon, 36 \\ avenue Guy de Collongue, BP 163, 69131 Ecully Cedex (France) \\ Y. Berthier, M. C. Dubourg and M. Godet \\ Laboratoire de Mécanique des Contacts (CNRS URA 856), Institut National des Sciences \\ Appliquées de Lyon, 20 avenue Albert Einstein, 69621 Villeurbanne Cedex (France)
}

\begin{abstract}
Materials fail through overstressing and overstraining. Overstressing leads to crack initiation and later propagation which can cause failure. Overstraining leads to material transformation, for instance strain hardening, followed by changes in material properties such as toughness loss.

This paper presents an overview of the work done in the last ten years on fretting, and illustrates these types of failure with respect to this particular form of damage. It divides the factors that govern overstressing and overstraining into three groups: the imposed conditions, the material properties and limits, and the material response. It places types of damage relative to each other on fretting maps. A flow chart starting from the imposed conditions and ending with failure, and showing all possible alternatives, is drawn.

The chart is then discussed in the light of fretting wear and fretting fatigue tests. It is shown that it is common during one test to cover both overstressing and overstraining conditions which complicates the interpretation of data. Static fretting fatigue which avoids that complication is therefore recommended.
\end{abstract}

\section{Introduction}

Fretting is one of the modern plagues of industrial machinery [1, 2]. It is sometimes responsible for premature fatigue failures and often limits component life [3, 4]. It occurs in quasi-static assemblies such as splines [5], cables [6,7], turbine blade assemblies [8], and in nuclear power plants [9]. It is easy to identify in steel contacts as it produces the well known "red powder".

Fretting is complex. In 1982, Beard [10] suggested that more than 50 parameters played a role in fretting and wrote that the subject was encumbered with misconceptions, half truths and sometimes downright errors. This paper attempts to present an overview of fretting as it appears today; it lists the questions to which satisfactory answers have been brought, and those that must be answered in the coming years.

\section{Damage, fretting wear and fretting fatigue}

Fretting damage is divided into fretting wear and fretting fatigue [1, 2]. Fretting wear starts when particles are detached from the rubbing surfaces or first-bodies. It 
leads to loss of clearance in many applications but can cause jamming when debris is trapped in the contact. It is common in distributed contacts such as flanged fittings, bearing housings etc. Fretting fatigue starts when cracks are initiated within or at the edge of the contacts. It leads to component failure as cracks propagate. It is found in concentrated contacts such as shaft keys, wire strands etc. Even though the origins of fretting fatigue and fretting wear are different, both forms of damage often coexist in the same contacts.

Some care must be exercised in terminology. It is common to talk about fretting wear when the contact load acts alone, or fretting fatigue when an external load, for instance a cyclic tensile load, is superimposed on the contact load. This can create some confusion as wear and cracks can be found in both types of loading.

\section{New developments}

A lot has been done in tribology, in materials science, in fracture mechanics, and in data presentation during the last ten years to clarify the subject and explain the contradictions referred to by Beard [10]. The new developments presented briefly below are centred around work performed during the last ten years by the Laboratoire de "Mécanique des Contacts" de l'Institut National des Sciences Appliquées (INSA) and by the Laboratoire "Matériaux-Mécanique Physique" de l'Ecole Centrale de Lyon (ECL) [11-14].

\subsection{Tribology}

Recent work $[15,16]$ has shown that a three-body contact can be broken down into five basic elements (Fig. 1): the two rubbing solids or first-bodies, the interface or third-body bulk, and the two screens that separate that bulk from the first-bodies. The screens and interface bulk form the third-body. These five basic elements are known as sites and are numbered $S_{1}$ to $S_{5}$. The difference in velocity between points $A$ and $B$ is thus accommodated along line $A B$. In each site, the velocity can be accommodated according to four different modes labelled respectively $M_{1}$ to $M_{4}$ and which correspond to the elastic, rupture, shear, and rolling modes. The combination of five sites and four modes leads to 20 velocity accommodation mechanisms (VAMs).

For instance, machine elements, test specimens and supports deform elastically $\left(S_{1} M_{1}\right.$ and $\left.S_{5} M_{1}\right)$. Elastic deformations also accommodate larger amplitudes when firstbody stiffness is reduced by cracks $\left(S_{1} M_{2}\right.$ and $\left.S_{5} M_{2}\right)$. Both these VAMs are common in fretting. Third-body sites $S_{2}, S_{3}$ and $S_{4}$ are also activated in fretting.

VAMs are useful as they focus on how and where the difference in velocity between rubbing solids is taken up. The concept is general, and is applicable to all contacts from lubrication to "dry wear" which can also be looked upon as a flow problem [17]. A friction problem is only understood when the activated VAMs are identified.

\subsection{Materials science and damage}

Materials fail through overstressing and overstraining. The relation between overstressing and overstraining when damage is present is not limited to classical stress-strain laws. Overstressing leads to crack formation or rupture either instantaneously or after fatigue. Material transformation is noted in the immediate crack lip vicinity; it is only observable by transmission electronic microscopy. Overstraining leads to microstructural transformations. In contact problems, these are called tribological 


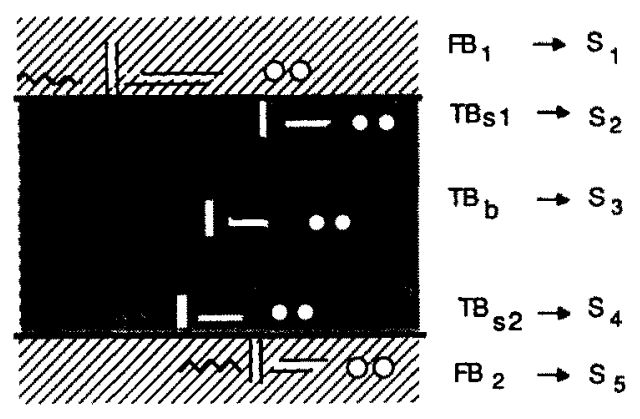

a) 5 Accommodation sites $S, \ldots . . . S_{5}$

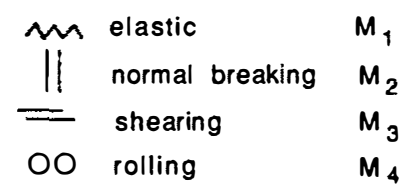

b) 4 Accommodation modes $M_{1} \ldots \ldots . . . M_{4}$

FB : First-Body : TB : Third-Body ;

TBb : Third-Body (bulk) ; TBs : third-body screen

Fig. 1. Velocity accommodation mechanisms (VAMs, $\mathrm{S}_{\mathrm{i}} \mathrm{M}_{\mathrm{j}}$ ) for three-body contacts.

transformed zones (TTZs). They are known to have mechanical properties significantly different from those of the original materials. TTZs are observable on classical optical microscopes after chemical etching [18]. Some of the difficulties in the interpretation of fretting results discussed above come from the fact that fretting failures can be caused by these two mechanisms.

Thus, two types of macroscopic degradations are found in contacts: in overstressing, crack initiation which is highly localized; in overstraining, the TTZ which covers the friction track. Both overstressing and overstraining are governed by surface and volume effects.

Progress in the understanding of fretting damage is thus impaired by changes in material properties which have not yet been quantified $[19,20]$. In low toughness materials, such as some ceramics and glasses, debris or cracks form rapidly as the first-bodies have little residual plasticity, and $A \%$, the percentage elongation to rupture, is low. For higher toughness materials, such as metals or metal alloys with high $A \%$, crack initiation or debris production is not instantaneous. Debris emerge from a very hard modified metallographic structure made out of very stable phases possessing fine grain size distributions $(\approx 250 \AA)$. The progressive drop in concentration of small tempering carbides $\left(\epsilon, \mathrm{M}_{2} \mathrm{C}\right)$ in steels and of the $\beta$ phase in titanium alloys, observed during rubbing tests, are common in low cycle fatigue tests. However, the very small grains found in the newly formed microstructure, along with the high level of cumulated plastic strain in the layers close to the surface, all point to the more complex dynamic recrystallization mechanism.

Dynamic recrystallization starts during the first passes of the wear test and the locally transformed (or consolidated) surface rapidly becomes unable to accommodate 
the deformation imposed by the contact load and it cracks. The material "shakes down" [21], and debris spring from the fragile transformed layer.

In fretting, cracks are initiated at the edge of the contact, and the tribological transformed zones are found in the contact zone. This signifies that the contact conditions are not the same in both locations and that during and after transformations the material properties are also different.

\subsection{Fracture mechanics}

Crack initiation is predictable as it is governed by overstressing [22-26]. Similar behaviours and results can therefore be expected from both well controlled friction and traction tests. The maximum internal tensile stress $\sigma_{x x}$, or skin stress, which is available for well defined geometries if load and traction are known, can therefore be compared with the tensile fatigue limit stress $\sigma_{\mathrm{D}}$ produced in classical material tests. This amounts to using a Wöhler type approach, with its fatigue limit $\sigma_{\mathrm{D}}$, which takes into account internal effects such as yield stress and toughness variations, and external effects such as environment, frequency etc. If $\sigma_{x x}<\sigma_{\mathrm{D}}$, initiation is avoided. If $\sigma_{x x}>\sigma_{\mathrm{D}}$, cracks are expected and the incubation time, which depends on both material toughness and rate of change of toughness (cyclic strain hardening), is also governed by the difference between these two values. For brittle materials, a similar approach can be used, based on the rupture stress $\sigma_{\mathrm{R}}$ rather than on $\sigma_{\mathrm{D}}$.

In most fatigue and fretting fatigue laboratory tests, the entire test specimen is stressed. Any crack formation therefore decreases the effective section of the specimen and crack initiation normally leads to propagation and failure, as the stress intensity factors (SIFs) $K_{\mathrm{I}}$ rise during the test. The situation is different in industrial contacts where, because of design, the stresses are high in the contact vicinity but drop rapidly away from that zone. Under these conditions, recent work has shown that the SIFs $K_{\mathrm{I}}$ and $K_{\mathrm{II}}$ decrease as cracks grow out of the high stress region, and that propagation can stop [27-30]. The same work has also shown that under fretting conditions, cracks are often closed and that propagation, if any, occurs most likely in mode 2 . This is important from a design point of view as cracks do not necessarily propagate in practice even though they do in laboratory rigs.

\subsection{Friction logs and fretting maps}

Curves giving the variation of the coefficient of friction against time or number of cycles do not produce evidence which can be used to determine the activated VAMs. Friction logs are much more powerful. In a three-dimensional friction log (Fig. 2 ), the tangential force $F$ is recorded as a function of the imposed displacement $D$ for each cycle and of the number of cycles. Load, frequency, amplitude, contact geometry, material combination and environment are specified in each log. Figure 2 shows a classical friction log obtained with steel specimens. It is made out of individual force-displacement (FD) cycles, or friction loops, which take on different shapes (Fig. 3): a closed (cc) conservative FD cycle, associated with elastic accommodations $\left(\mathrm{S}_{1} \mathbf{M}_{1}\right)$; tangential contact stiffness is given by the slope of the FD line; an elliptic (ec) slightly dissipative FD cycle, found in contacts which exhibit either partial slip or interfacial crack friction or both $\left(S_{1} M_{2}\right.$ and $\left.S_{3} M_{7}\right)$; a trapezoidal (tc) cycle, characteristic of gross slip; the near horizontal segments are dissipative $\left(S_{3} M_{7}\right)$, the near vertical segments correspond to the elastic displacements $\left(S_{1} M_{1}\right)$ noted above.

Fretting maps were originated by Vingsbo and coworkers [31, 32]. They isolated three fretting regimes: stick, mixed stick and slip, and gross slip. Here [33, 34], two fretting maps (Fig. 4) are drawn from families of friction logs, i.e. logs drawn for 


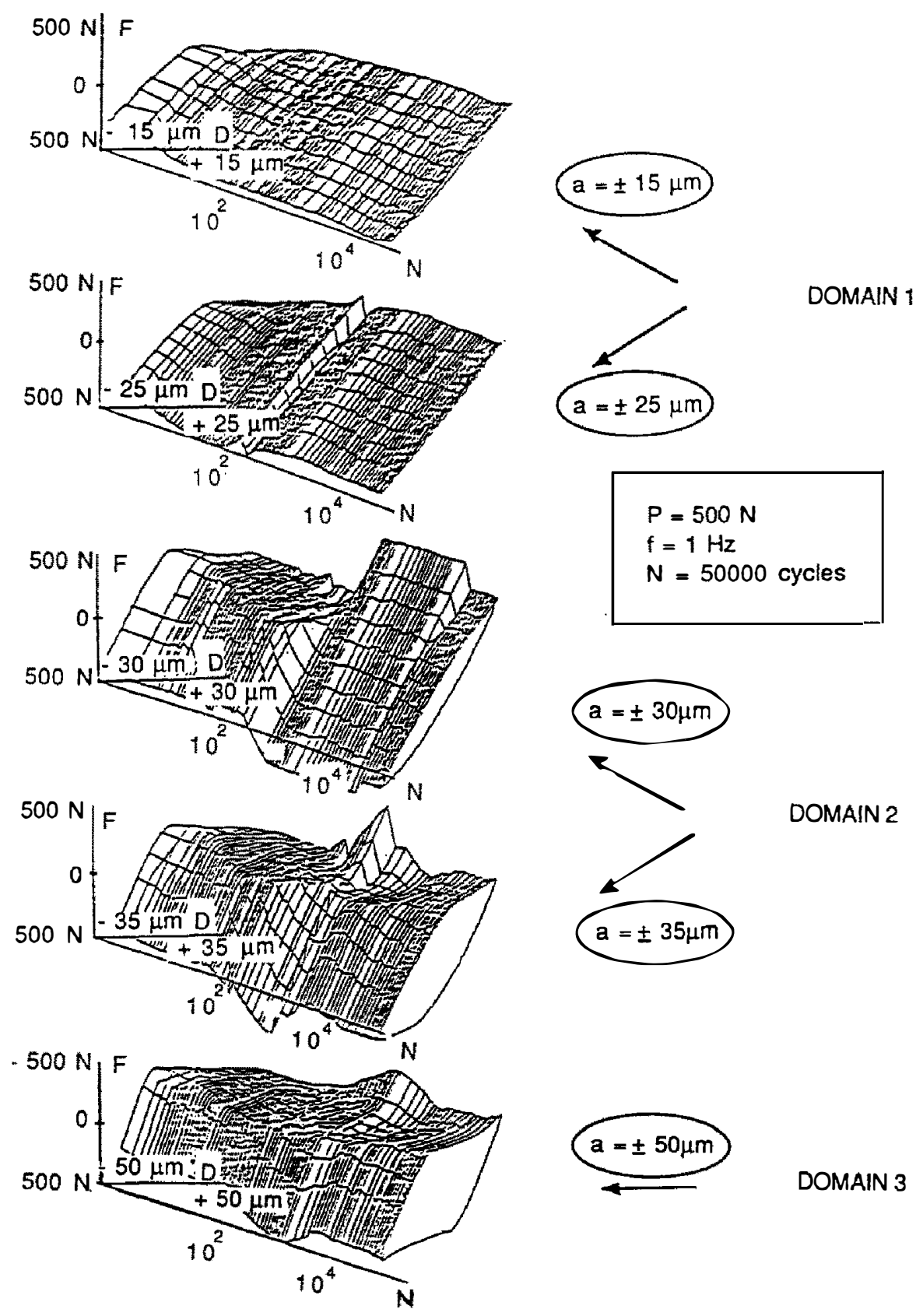

Fig. 2. Three-dimensional friction logs obtained for different amplitudes with $\mathbf{7 0 7 5}$ aluminium alloys.

different amplitudes and loads. The first, the running condition fretting map (RCFM) plots loads $P$ vs. nominal amplitude for a given frequency and a given roughness. Zones of stick, partial slip and gross sliding are also identified. It is close to the 


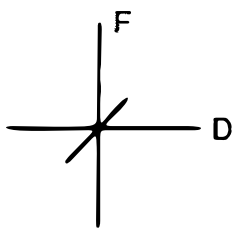

DOMAIN 1

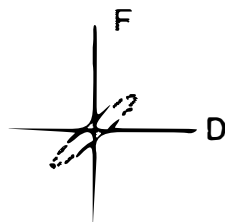

DOMAIN 2

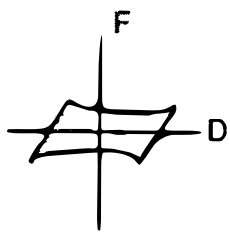

DOMAIN 3

Closed cycle (c.c)

Elliptical cycle (e.c)

Trapezoïdal cycle (t.c)

Fig. 3. Characteristic friction loops.

Stage 1

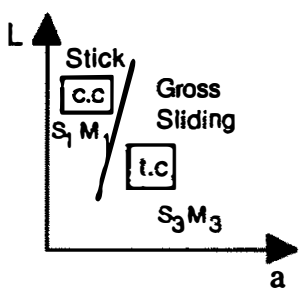

Stage 2

L

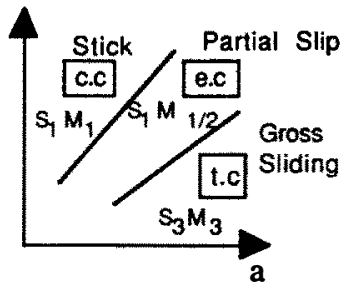

Stage 3

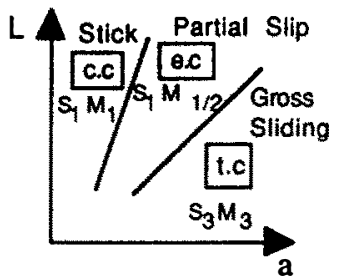

Running Condition Fretting Maps (L : Load, a : Amplitude)

$\{S\}$

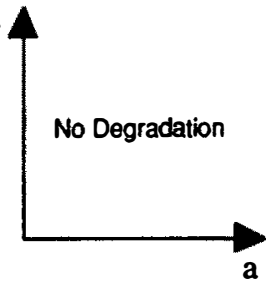

\{S\}

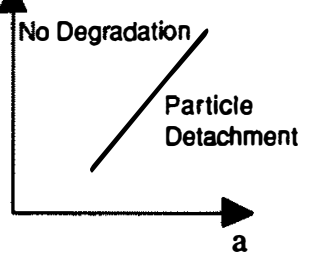

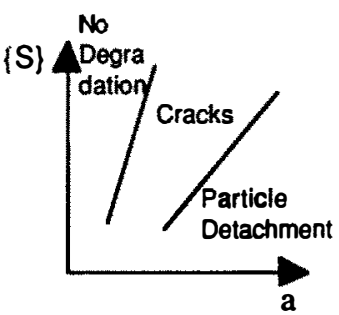

Material Response Fretting Maps (S : Stress, a : Amplitude)

lig. 4. Running condition and material response fretting maps.

Vingsbo map, except for the fact that it has been drawn for a different number of cycles, which shows that the three zones vary in extent during the test. The second, the material response fretting map (MRFM), plots stress or equivalent stress vs. amplitude. Three zones are also identified in these maps: no degradation, cracks and particle detachment zones. The second map is also shown to vary during the test, along with the effective VAMs and the material properties. Running conditions, material response and VAMs are intimately related.

Even if drawn with the same axes, the zones isolated in RCFMs and MRFMs do not superimpose, even though particle detachment is usually associated with gross slip, cracking is usually associated with partial slip, and no degradation is usually associated with no slip. As an example, unlike aluminium alloys which yield large cracks, fatigue-resistant titanium alloy MRFMs do not exhibit cracks under partial slip conditions. 
Representative types of RCFMs and MRFMs, drawn schematically in Fig. 4, show that these maps give both guides and trends. The frontiers between zones are not as clear as indicated, since the transition from one zone to the other is gradual; they vary during the test, particularly for the crack domain related to overstressing.

Fretting maps serve today to identify contact kinematic conditions (adhesion, partial slip, gross slip). Partial slip clearly appears as the most detrimental mode for crack initiation. Critical values of slip amplitude were found for which fretting fatigue crack propagation is high and in all likelihood lifetime is minimal [33].

\subsection{Conclusions}

The developments presented above throw a different light on the interpretation of fretting data and their transposition to industrial conditions. Advances in tribology point to the necessity of identifying the velocity accommodation mechanisms. The introduction of both friction logs and friction maps presents data which are very much richer than those given by standard friction curves. The awareness of changes in material properties during testing is necessary to understand changes observed in material behaviour. The extension of fracture mechanics to real contact situations explains behaviours which were not clear earlier.

Unfortunately, all these advances underline the complexity of the entire fretting process and point to the many factors both imposed by the test, and induced by the test running conditions which govern fretting damage. They also point to the difficulty of running a meaningful fretting experiment under both fretting wear and fretting fatigue conditions.

\section{Governing parameters}

Section 3 confirmed that fretting damage is governed by many parameters. This section tries to organize some of them around a flow chart. The parameters identified during experimental campaigns are divided in three groups: imposed running conditions, material properties and limits, and induced running conditions.

\subsection{Imposed nunning conditions}

The imposed running conditions are those imposed by the test device and the operator.

\begin{tabular}{lll}
\hline Parameters & Units & Observations \\
\hline Loads & $\mathrm{N}$ & Contact and external \\
Amplitude & $\boldsymbol{\mu m}$ & \\
Frequency & $\mathbf{H z}$ & \\
Temperature & ${ }^{\circ} \mathrm{C}$ & \\
Environment & Composition & \\
\hline
\end{tabular}

Loads are sometimes expressed in terms of pressure $(\mathrm{Pa})$. The contact load acts within the fretting contact, and the external load takes in all loads, seen by the fretting structure, other than the fretting contact load. Contact loads are usually constant, external loads often vary. Temperature and environment are listed as governing parameters, but their effects are not discussed here. 


\subsection{Material properties and limits}

The material properties and limits listed have been shown to play an important role in orienting the test towards one form of damage or another.

\begin{tabular}{lll}
\hline Parameters & Units & Observations \\
\hline$K_{\text {ith }}(i=1,2)$ & Pa m & SIF threshold \\
$A \%$ & Non-dimensional & Percentage elongation to fracture \\
$\sigma_{\mathrm{D}}$ & $\mathrm{Pa}$ & Wöhler fatigue limit \\
$\sigma_{\mathrm{R}}$ & $\mathrm{Pa}$ & Rupture strength \\
$\epsilon_{\mathrm{y}}$ & Non-dimensional & Yield strain \\
\hline
\end{tabular}

The Wöhler fatigue limit $\sigma_{\mathrm{D}}$ is taken here in a broad sense as the stress needed for both crack initiation and crack propagation. This is acceptable in classical fatigue tests which exhibit simple stress patterns in which most cracks propagate after initiation. It is not so in all fretting applications as the stress pattern induced by contact loads can be quite complex. All other terms are self explanatory. Some of these parameters, $A \%$ for instance, vary during the test because of cyclic strain hardening. As mentioned in Section 3.3, the rupture strength $\sigma_{\mathrm{R}}$ is considered for brittle materials, which can fail during the first cycle.

\subsection{Induced nunning conditions}

\begin{tabular}{lll}
\hline Parameters & Units & Observations \\
\hline$\sigma_{\mathrm{xx}}$ & $\mathrm{Pa}$ & Skin stress \\
$\epsilon_{\mathrm{xx}}(i=1,2)$ & Non-dimensional & Deformation \\
$a_{\mathrm{ci}}(i=1,2)$ & $\mu \mathrm{m}$ & Critical amplitudes \\
$K_{i}(i=1,2)$ & Stress intensity factors \\
\hline
\end{tabular}

$\sigma_{x \alpha}$ is the internal surface stress (Fig. 4) which is strongly dependent on friction. Critical amplitudes $a_{\mathrm{c} 1}$ and $a_{\mathrm{c} 2}$ have no scientific definition to date. They mark the frontiers determined experimentally which separate the different damage domains indicated in the fretting maps. Critical amplitudes are not intrinsic material properties, they depend on test devices, running conditions and particularly on loads and material combinations. Other parameters are self explanatory.

\section{Fretting chart}

Figure 5 indicates how the combination of imposed and induced conditions and material properties interact. A ball on flat geometry is chosen as it is simple to analyse. All conditions, the material combination, roughness, frequency, environment are fixed. Only the fretting amplitude $a$ is varied in this analysis. Load effects are discussed. Two critical amplitudes $a_{\mathrm{c} 1}$ and $a_{\mathrm{c} 2}$, where $\mathrm{a}_{\mathrm{c} 2}>a_{\mathrm{c} 1}$, are identified which define three domains:

$\begin{array}{lll}\text { domain 1 } & a<a_{\mathrm{c} 1} & \text { (no slip) } \\ \text { domain 2 } & a_{\mathrm{c} 1}<a<a_{\mathrm{c} 2} & \text { (partial slip) } \\ \text { domain 3 } & a>a_{\mathrm{c} 2} & \text { (gross slip) }\end{array}$




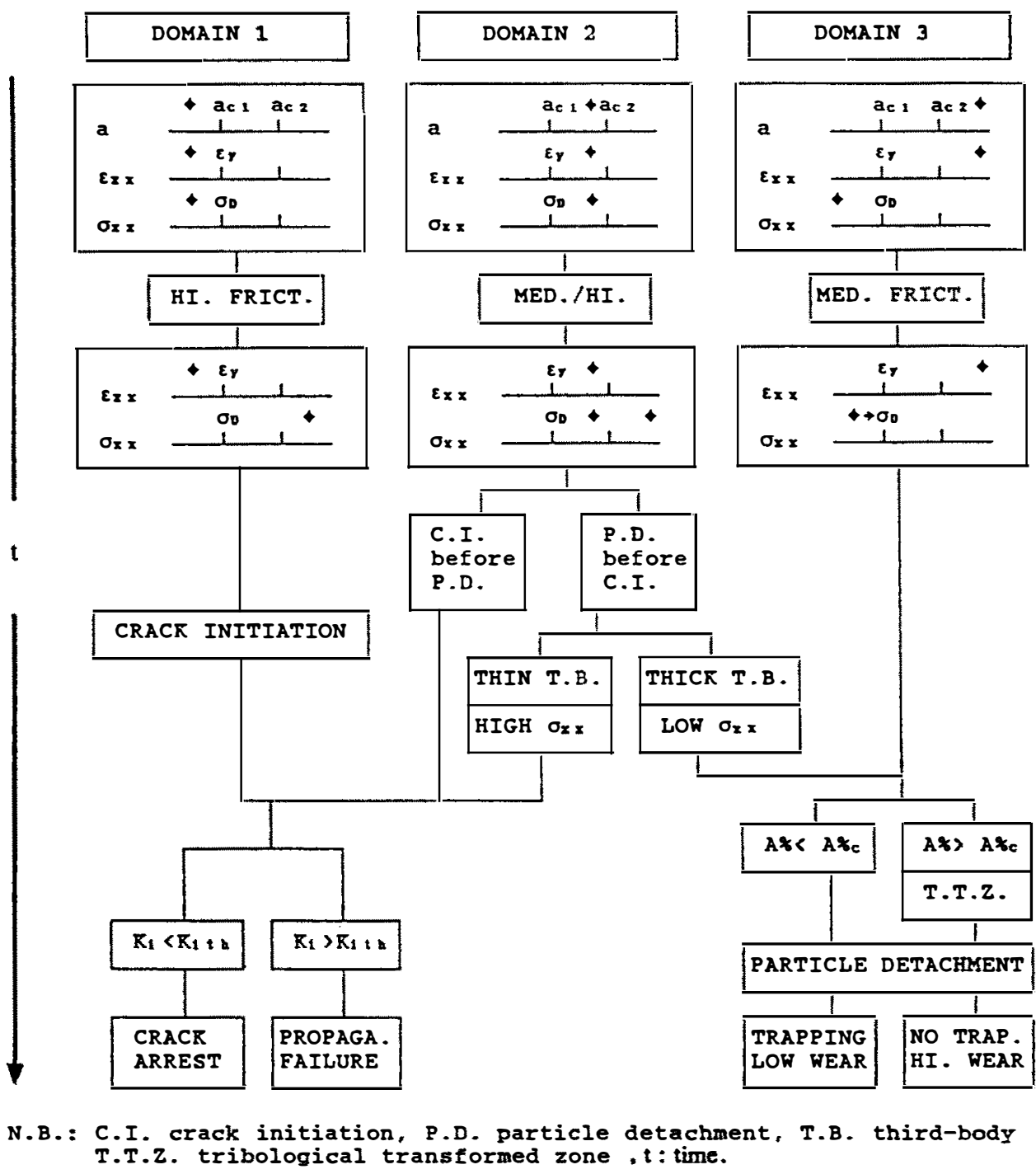

Fig. 5. Fretting chart: crack initiation and propagation, high and low wear.

The amplitude refers to the nominal amplitude imposed on the machine and not to the actual slip at contact. The two are known to differ significantly [11], owing to different forms of velocity accommodation. The critical slip necessary to cause damage often discussed in the literature [35] is the measure of elastic accommodation of the test device, specimen and specimen supports. This is expressed in Fig. 5 by setting the critical amplitude $a_{\mathrm{cl}}$ (a machine parameter), opposite the yield strain $\epsilon_{\mathrm{y}}$ (a material parameter), even though the deformation $\epsilon$ is not constant along the contact. 
The definitions given above for critical amplitudes $a_{\mathrm{c} 1}$ and $a_{\mathrm{c} 2}$ are indicative. They imply that below $a_{\mathrm{c} 1}$ the relative displacement at contact is close to zero, and that beyond $a_{\mathrm{c} 2}$ significant slip is observed. Values of around 15 and $50 \mu \mathrm{m}$ are commonly observed respectively for $a_{\mathrm{c} 1}$ and $a_{\mathrm{c} 2}$; they can be determined from examination of the loops (Fig. 3) in the friction log (Fig. 2). A closed loop is representative of domain 1, a parallelogram of domain 3 and intermediate quasi-elliptical loop of domain 2 . Critical amplitudes are of the order of magnitude of tolerances in machines which explains why they vary from one device to another. For low stiffness machines values of up to $100 \mu \mathrm{m}$ were noted.

Figure 5 lists the three domains. Yield strain $\epsilon_{y}$ and fatigue limit $\sigma_{D}$ are marked respectively on the deformation and the stress lines of each domain. Critical amplitudes $a_{\mathrm{c} 1}$ and $a_{\mathrm{c} 2}$ are also noted on the amplitude lines at the top of the figure for each domain. They are kept constant during the test. As noted in Section 3.2, the abscissa of the crack initiation and transformed zones are not the same and, owing to different histories, the material properties are different in both locations. It is therefore not possible to set the stress and the deformation lines by aligning for instance the yield stress $\sigma_{y}$ (not shown) and the yield strain $\epsilon_{\mathrm{y}}$. The relative positions of lines $\sigma$ and $\epsilon$ vary during the test and of course from one material to another. The black diamonds on the $\epsilon_{\mathrm{xx}}, \sigma_{\mathrm{xx}}$ and $a$ axes locate these parameters with respect to references $\epsilon_{\mathrm{y}}, \sigma_{\mathrm{D}}$ and $a_{\mathrm{c} i}$.

As expressed in Fig. 5, domains 1, 2 and 3 can be redefined in terms of $\sigma$ and $\epsilon$ instead of $a_{\mathrm{c} i}$. In domain $1, \epsilon_{\mathrm{xx}}<\epsilon_{\mathrm{y}}$, in domain 3, $\sigma<\sigma_{\mathrm{D}}$. Different combinations are found in domain 2 which is defined for conditions where $\epsilon_{x x}>\epsilon_{y}$ and $\sigma_{x x}>\sigma_{D}$.

The situations observed experimentally in domains 1 and 3 are well differentiated and can be presented relatively simply. Two examples are given. Results noted in domain 2 are not as clear as they combine the tendencies found in the two others. Domains 1 and 3 will therefore be presented first.

\subsection{Domain 1: crack formation $\left(\epsilon_{x x}<\epsilon_{y}\right)$}

(1) Friction is usually low $(f \approx 0.1)$ at the start $\left(\sigma_{x x}<\sigma_{D}\right)$, pollution screens are rapidly disrupted, and two-body contact is established locally. As relative motion is negligible, adhesion is strong and static friction rises to reach high values $(f \approx 2)$ after less than 100 cycles.

(2) At the contact exit, in a ball on flat contact, $\sigma_{x x}$ is given by:

$\sigma_{\mathrm{xx}}=-p_{0}\left\{\left(1-x^{2} / a^{2}\right)^{1 / 2}+2 f x / a\right\}$

At contact edges, for $x= \pm a, \sigma_{x x}$ varies between $+2 f p_{0}$ and $-2 f p_{0}$. As $p_{0}$ is around $1 \mathrm{GPa}$, and $f$ is of the order of 1 or $2, \sigma_{\mathrm{xx}}$ alternates between +4 and $-4 \mathrm{GPa}$ which is considerable. The material fatigues and cracks are initiated when $\sigma_{x x}>\sigma_{\mathrm{D}}$. This can take up to $10^{5}$ cycles. If $\sigma_{x x}<\sigma_{\mathrm{D}}$ (case not illustrated in Fig. 5), no cracks are initiated, and the operation can go on without damage. With brittle materials cracks can occur immediately if $\sigma_{\mathbf{x x}}$ is larger than the rupture strength $\sigma_{\mathbf{R}}$.

(3) Cracks propagate after initiation if the stress intensity factors $K_{i}(i=1,2)$ are larger than their threshold values $K_{i t h}$. As $K_{i}$ varies with crack length and with the stress field near the crack tip, it can either propagate and lead to component rupture or stop.

\subsection{Domain 3: particle detachment}

(1) Friction is also usually low $(f \approx 0.1)$ at the start, but pollution screens are rapidly disrupted, and two-body contact is established locally. Relative motion is no 
longer negligible, adhesion is less strong than in domain 1 and the dynamic coefficient of friction rises to $f \approx 1$ after less than 100 cycles and levels off.

(2) High rates of deformation $\left(\epsilon_{x x} \gg \epsilon_{y}\right)$ are imposed on the material within the contact zone over a thickness of between 10 and $100 \mu \mathrm{m}$. If the percentage elongation to fracture $A \%$ of the material of the contact is small, the contact zone breaks up and debris is produced quasi-instantly. If $A \%$ is high, the material strain hardens, goes through a transformation phase (Section 3.2 ) and only then produces debris. Phase transformation can postpone debris formation until after 1000 cycles.

(3) The rest of the test is governed by the factors that control particle trapping and elimination from the contact. If the rate of elimination is high and debris circulation avoided, wear is high, component function is lost by increased clearance which leads to shocks, noises and other nuisances. If the rate of elimination is low, satisfactory component life can be expected.

\subsection{Domain 2: mixed crack formation and particle detachment}

Domain 2, where $\epsilon_{\mathrm{xx}}>\epsilon_{\mathrm{y}}$ and $\sigma_{\mathrm{xx}}>\sigma_{\mathrm{D}}$, is characterized by the competition between crack formation and particle detachment. Both forms of damage are observed. Two cases are identified.

(1) Crack formation precedes particle detachment, with $\sigma_{x x} \gg \sigma_{D}$ or $\sigma_{x x}>\sigma_{R}$ and $\epsilon_{x x}>\epsilon_{y}$. This condition is characteristic of low toughness materials. Cracks form, specimen stiffness drops, the effective amplitude also drops, $\epsilon_{x x}$ can reach or go below $\epsilon_{y}$. The process is then similar to that described for domain 1 which, depending on the relative values of $K_{i}$ and $K_{i \text { th }}$, leads either to crack propagation and failure or to crack arrest which guarantees satisfactory operating conditions.

(2) Particle detachment precedes crack formation, with $\sigma_{x x}>\sigma_{D}$ and $\epsilon_{x x} \gg \epsilon_{y}$. This condition is characteristic of high toughness materials. If the particle bed or thirdbody (TB) formed is thin, the skin stress $\sigma_{x x}$ stays constant and the SIFs remain high. The process is again similar to that described for domain 1. If the third-body is thick, $\sigma_{x x}$ drops, initiation can be avoided or not. If avoided, the SIFs are still low and the process follows the path described in domain 3.

As noted earlier, critical amplitudes depend on material and test device compliance, friction and running conditions. The critical amplitudes drop for instance as the load increases. The three domains presented here are representative of many materials, including steel, aluminium alloys etc. With fatigue-resistant alloys such as titanium alloys (Ti-6Al-4V) which are less sensitive to crack initiation and propagation, domains 1 and 2 do not always exist under representative running conditions. Either no degradation or particle detachment (domain 3 ) is observed.

\section{Fretting test devices}

Fretting fatigue simulators differ from fretting wear devices in that external body forces modify the stress pattern imposed by the contact load. Classical simulators are modified traction machines in which the tensile specimen, which is subjected to an ordinary fatigue test cycle, is also loaded laterally by two fixed friction pads. The relative motion between tensile specimen and pads is governed by specimen extension and machine compliance. The idea is very attractive as it is easy to compare Wöhler curves obtained with and without pads and produce a figure which is believed to be 
characteristic of the life reduction induced by fretting. The device has however been heavily criticized from quite different angles.

(1) The design engineer notes that the life reduction predicted from fretting fatigue tests is much higher than that noted in practice.

(2) The tribologist observes that the test conditions are not controlled. Interfacial slip, which has been shown earlier to determine the type of damage produced, varies with the tensile load variation imposed by the Wöhler test program and with the friction force which cannot be controlled. The test conditions vary from one material to another because the tensile specimen elongation, and thus up to a point the interfacial slip, is a linear function of Young's modulus $E$. They are not representative, and extrapolation to practice is hazardous.

(3) The material experts note that friction pad action overstresses the tensile specimen and that part of the life reduction can be attributed to overloading and not only to friction and surface effects.

These points cannot be brushed aside easily. Indeed, the change in length $u$ at mid-height (where the friction pads act) of a $15 \mathrm{~cm}$ steel tensile specimen subjected to a tensile stress of $100 \mathrm{MPa}$ (or an alternating stress of $\pm 50 \mathrm{MPa}$ ) is given by the elementary formula:

$u=\epsilon_{\mathrm{xx}} l$

where $\epsilon_{x x}=\sigma_{x x} / E$ with $\sigma_{x x}=100 \times 10^{6} \mathrm{~Pa}, E=20 \times 10^{10} \mathrm{~Pa}, l=0.15 / 2 \mathrm{~m}, u=37.5 \times$ $10^{-6} \mathrm{~m}$.

The figure is roughly doubled for aluminium. Values of between 10 and $50 \mu \mathrm{m}$ are close to those given as representative of critical amplitudes $a_{\mathrm{c} 1}$ and $a_{\mathrm{c} 2}$ in Section 4.4. They of course have to be adjusted to take into account the factors of machine and support compliance etc. mentioned earlier which account for the difference between imposed displacement and actual slip. It is, however, safe to say that the conditions imposed in fretting fatigue simulators span over the range of conditions which can orient the test towards either crack initiation and propagation or particle detachment. Unfortunately, these conditions are not specified for each machine.

To avoid this problem, and transpose the methodology which is centred around running condition fretting maps (RCFM) and material response fretting maps (MRFM), it is best to run systems in which the "body" and "contact" loads and amplitude are controlled separately. This can be achieved in "fretting-static fatigue" tests in which body stress is constant $\left(R=\sigma_{\min } / \sigma_{\max }=1\right)$ and the slip amplitude is controlled. Fretting maps are then plotted for different loads and different amplitudes, at different numbers of cycles. If the test conditions are representative of those found in practice, both fretting maps can help designers, first to identify the type of damage expected for given materials operating under given conditions, second to favour one type of damage over another, by varying for instance component stiffness, and third to choose one palliative (coating) or another. For instance, to avoid fatigue failures which are the most dangerous, and which follow crack initiation, the designer should favour the elastic accommodation mechanism $\left(S_{1} M_{1}\right)$ or if this is not possible seek particle detachment $\left(\mathrm{S}_{3} \mathrm{M}_{3}\right)$. This last mechanism does open up the entire problem of debris trapping which is a study in itself and which is influenced by many parameters [36].

Life predictions can be made from fretting maps when cracking is the failure mechanism. Crack initiation duration and propagation rates in the contact zone are given by the data collected to plot the fretting maps at different times. Propagation to rupture can, outside of the contact zone, be predicted by classical propagation laws and models. 


\section{Conclusion}

Materials fail through overstressing and overstraining. Overstressing leads to crack initiation and later propagation which can cause failure. Overstraining which leads to material transformation (strain hardening), followed by changes in material properties (toughness loss) favours particle detachment. Overstressing can be related to the fatigue limit $\sigma_{\mathrm{D}}$, overstraining to the yield strain $\epsilon_{\mathrm{y}}$. In fretting, overstressing acts at the contact edge while overstraining operates within the contact itself.

The factors which govern overstressing and overstraining can be divided into three groups: the imposed conditions, the material properties and limits, and the material response. This presentation situates one type of damage with respect to another on fretting maps. A flow chart starting from imposed conditions and ending with failure, and showing all possible alternatives, was drawn.

The chart was then discussed in the light of fretting wear and fretting fatigue tests. It was shown that it is common during one test to cover both overstressing and overstraining conditions, which complicates the interpretation of data. Static fretting fatigue which avoids that complication is therefore recommended.

The arguments presented show that, to interpret correctly the data provided in fretting tests and rearranged in fretting maps, and to extrapolate them to an industrial problem, it is necessary to carry out the following steps: identify as closely as possible the contact operating conditions (contact and body forces, amplitude, ...) of the industrial components under study; situate them with respect to those tested in the fretting maps; identify failure mechanisms rather than try to obtain a factor supposedly representative of the drop in fatigue limit to be included in component life predictions; include materials on which practical or prototype information is available to verify the correlation between laboratory tests and practice.

\section{References}

1 R. B. Waterhouse, Fretting Fatigue, Elsevier Applied Science, London, 1981.

2 R. B. Waterhouse, Fretting Corrosion, Pergamon, Oxford, 1972.

3 P. J. E. Forsyth, Occurrence of fretting fatigue failures in practice. In R. B. Waterhouse (ed.), Fretting Fatigue, Elsevier Applied Science, London, 1981, pp. 99-125.

4 D. W. Hoeppner, Fretting of aircraft control surfaces, AG ARD Conf. Proc. No 161, AGARD, Munich, 1974.

5 P. M. Ku and M. L. Valtierra, Spline wear - effects of design and lubrication, ASME J. Eng. Ind., (1975) 1257-1265.

6 B. R. Pearson, P. A. Brook and R. B. Waterhouse, Fretting in aqueous media, particularly of roping steels in seawater, Wear, 106 (1985) 225-260.

7 G. Lofficial and Y. Berthier, L'usure dans les cables et conduits fiexibles, une étude de cas en tribologie, Eurotrib, September 1985, Vol. 3, Ecole Centrale de Lyon, pp. 2.2.1.-2.2.5.

8 C. Chamont, Y. Honnorat, Y. Berthier, M. Godet and L. Vincent, Wear problems in small displacements encountered in titanium alloy parts in aircraft turbomachines, Proc. Sixth World Conf. on Titanium, June 6-9, 1988, Cannes, in P. Lacombe et al. (eds.), Société Française de Métallurgie, Editions de Physique, 91944 Les Ulis, France.

9 D. H. Jones, A. Y. Nehru and J. Skinner, The impact fretting wear of a nuclear reactor component, Wear, 106 (1985) 139-162.

$10 \mathrm{~J}$. Beard, An investigation into the mechanism of fretting fatigue, Ph.D. Thesis, University of Salford, 1982.

11 Y. Berthier, L. Vincent and M. Godet, Fretting fatigue and fretting wear, Tribol. Int., 22 (4) (1989) 235-242. 
12 L. Vincent, Y. Berthier and M. Godet, Fretting wear and fretting fatigue damage, Fatigue 1987, EMAS, Charlottesville, PA, USA, Vol. 1, 1987, pp. 567-574.

13 Y. Berthier, L. Vincent and M. Godet, Velocity accommodation in fretting, Wear, 125 (1988) 25-38.

14 Ch. Colombié, Y. Berthier, A. Floquet, L. Vincent and M. Godet, Fretting: load-carrying capacity of wear debris, ASME J. Tribol., 106 (2) (1984) 185-194.

15 Y. Berthier, Experimental evidence for friction and wear modelling, Wear, 139 (1990) 77-92.

16 Y. Berthier, L. Vincent and M. Godet, Velocity accommodation sites and modes in tribology, in the press.

17 M. Godet and Y. Berthier, Continuity and dry friction: an Osborne Reynolds approach. In D. Dowson, C. M. Taylor, M. Godet and D. Berthe (eds.), Fluid film lubrication - Osborne Reynolds Centenary, Elsevier, Amsterdam, 1987, Fig. 16.

18 S. Fayeuille, P. Blanchard and L. Vincent, Fretting wear behaviour of several titanium alloys, Proc. STLE Annu. Meet., Montreal, May 1990, in STLE Trans., in the press.

19 D. W. Hoeppner and G. L. Goss, Metallographic analysis of fretting fatigue damage in Ti-6Al-4V-MA and 7075-T6 aluminium, Wear, 62 (1980) 287-297.

20 Y. Berthier, L. Vincent and M. Godet, Fretting fatigue and fretting wear, Tribol. Int., 22 (4) (1989) 235-242.

21 K. L. Johnson, Contact Mechanics, Cambridge University Press, Cambridge, 1985, pp. 286-294.

22 K. L. Johnson and J. J. O'Connor, Mechanics of fretting, Proc. Inst. Mech. Eng., 178 (3J) (1964) 7-21.

23 T. C. Chivers and S. C. Gordelier, Fretting fatigue and contact conditions: a rational explanation of palliative behaviour, Proc. Inst. Mech. Eng., 199 (C4) (1985) 325-337.

$24 \mathrm{~J}$. J. O'Connor, The role of elastic stress analysis in the interpretation of fretting fatigue failures. In R. B. Waterhouse (ed.), Fretting Fatigue, Elsevier Applied Science, London, 1981, pp. 23-66.

$25 \mathrm{~K}$. Endo and H. Goto, Initiation and propagation of fatigue cracks, Wear, 38 (1976) 311-324.

26 J. K. Lancaster, Crack propagation and particle detachment in the wear of glass under elastic contact conditions. In D. Dowson, C. M. Taylor, M. Godet and D. Berthe (eds.), Interface Dynamics, Tribology Series 12, Amsterdam, 1988, pp. 111-119.

27 D. A. Hills, D. Nowell and J. J. O'Connor, On the mechanics of fretting fatigue, Wear, 125 (1988) 39-52.

28 M. C. Dubourg and B. Villechaise, Unilateral contact analysis of a crack with friction, Eur. J. Mech. A, 8 (4) (1989) 309-319.

29 M. C. Dubourg, M. Mouwakeh, B. Villechaise and M. Godet, Crack behaviour under cyclic loading. In D. Dowson, C. M. Taylor, M. Godet and D. Berthe (eds.), Interface Dynamics, Elsevier, Amsterdam, 1988.

30 M. C. Dubourg and B. Villechaise, Analysis of multiple fatigue cracks, part I (theory) and II (results), ASME J. Tribol., in the press.

31 O. Vingsbo and D. Soderberg, On fretting maps, Wear, 126 (1988) 131-147.

32 O. Vingsbo, M. Odfalk and N. E. Shen, Fretting maps and fretting behavior of some FCC metal alloys, Wear Mater., (1989) 275-282.

33 V. Pellerin, Etude du comportement en usure induite sous petits débattements d'alliages d'aluminium et de titane, Thèse, Ecole Centrale de Lyon, Lyon, 1990.

34 Z. R. Zhou, S. Fayeuille and L. Vincent, Fretting of aluminium alloys, Wear, to be published.

35 P. J. Kennedy, L. Stallings and M. B. Peterson, A study of surface damage at low-amplitude slip, ASLE Trans., 27 (4) (1984) 305-312.

36 M. Godet, The third-body approach: a mechanical view of wear, Wear, 100 (1984) 437-452. 